\title{
A NEW METHOD OF STANDARDIZING DEATH RATES
}

\author{
BY \\ D. KERRIDGE \\ Medical Research Council Group for Epidemiological Research on Respiratory Diseases (Air Pollution), The University, \\ Sheffield.
}

Two methods of standardizing death rates for age are in common use, the "direct" and the "indirect" Both of these methods require a detailed knowledge of the age structure of the population in which the deaths occur, and the direct method requires the age structure of the deaths in addition. A third method is now suggested which requires only detailed knowledge of age structure of the deaths themselves. This method might conveniently be called Inverse Standardization.

The rate is calculated for each age group in some suitable standardizing population. For deaths, the standardizing population will usually be the whole population of England and Wales.

For any one age group, the number of deaths observed divided by the standard rate for that age group gives an estimate of the size of the group from which the deaths are drawn. The sum of these estimates gives an estimate of the total number in the population. This estimate will be too high if the death rates in the population are higher than the standard death rates, and conversely. The ratio of the estimate of the population to the true number in the population, expressed as a percentage, gives an index of the healthiness of the population, which may conveniently be called the "Inverse Standardized Mortality Ratio".

In a population for which each age-specific death rate is in the same ratio to the corresponding rate in the standard population, the three different methods of standardization give exactly the same result. When the ratios are different, the standard methods give considerably more weight to differences in the higher age groups, while the new method gives weight in proportion to the total number at risk in each age group. This would probably be an advantage in the study of, for instance, occupational mortality, where, as the "Decennial Supplement for 1951" (Registrar General, 1954a) points out, "the swamping effect of the inevitably high mortality" of the older age groups may obscure occupational differences in some circumstances.

The Standard Error of an "Inverse S.M.R" is usually higher than that of the corresponding ordinary S.M.R., especially if one or more of the age-specific death rates in the standardizing population is much lower than the others. For this reason it would not.be a suitable index for mortality in a population containing both children and adults.

In general, the usefulness of the Inverse S.M.R lies in its power to use information that would be inadequate for other methods. For instance, in analysing the death rates of a county borough, the age structure of social class groups or municipal ward populations is rarely known, but the total populations are available. When it is possible to use the ordinary S.M.R, however, this is to be preferred, as its standard error is smaller.

If $R_{1}, R_{2} \ldots$ etc. are the age-specific rates in the standardizing population, $x_{1}, x_{2}, \ldots$ etc. are the number of deaths observed in the population being studied, and $\boldsymbol{P}$ is the total number at risk,

The inverse S.M.R. is:

$$
\frac{100}{P} \times\left(\frac{x_{1}}{R_{1}}+\frac{x_{2}}{R_{2}} \ldots\right)
$$

and its standard error is:

$$
\frac{100}{P} \times \sqrt{\left(\frac{X_{1}}{R^{2}}+\frac{x_{2}}{R^{2}}{ }_{2} \cdot\right)} .
$$

\section{JUSTIFICATION FOR THESE FORMULAE}

Let $p_{1}, p_{2}, \ldots$ be the number of persons in each age group in the population being studied.

The expected value of $x_{i}$, on the assumption that this population is not different from the standardizing population, is $p_{i} R_{i}$ (where $i$ takes the values $1,2, \ldots$ etc.). 
The expected value of the inverse S.M.R is therefore:

$$
\begin{aligned}
\frac{100}{P} \times & \left(\frac{p_{1} R_{1}}{R}+\frac{p_{2} R_{2}}{R_{2}}+\ldots\right) \\
& =\frac{100}{P}\left(p_{1}+p_{2}+p_{3}+\ldots\right)=100,
\end{aligned}
$$

and is therefore independent of the age structure of the population.

To a first approximation, the number of deaths $x_{i}$ may be taken to be normally distributed with variance $x_{i}$, so that $\frac{x_{i}}{R_{i}}$ has variance $\frac{x_{i}}{R_{i}{ }^{2}}$.

The approximation is a little crude, but it is usual in this type of work. For example, the "Decennial Supplement for 1951" (Registrar General, 1954b) gives a variance for the inverse S.M.R. of:

$$
\left(\frac{100}{P}\right)^{2}\left(\frac{x_{1}}{R_{1}^{2}}+\frac{x_{2}}{R_{2}^{2}}+\ldots\right)
$$

and the standard error is:

$$
\frac{100}{P} \sqrt{\left(\frac{x_{1}}{R_{1}^{2}}+\frac{x_{2}}{R_{2}^{2}}+\ldots\right)} \text {. }
$$

\section{Calculation}

COMPARISON OF THE INVERSE AND ORDINARY S.M.R

The figures, taken from the "Statistical Review England and Wales for 1954" (Registrar General, 1955), represent the deaths from bronchitis for men aged $25+$ in rural areas. The standardizing population is the whole population of England and Wales for the same year.

(a) Calculation of Indirect S.M.R

\begin{tabular}{l|c|c|c}
\hline $\begin{array}{c}\text { Age } \\
\text { (yrs) }\end{array}$ & $\begin{array}{c}\text { Population at } \\
\text { Risk } \\
\text { (thousands) }\end{array}$ & $\begin{array}{c}\text { Standard Rate } \\
\text { (per thousand) }\end{array}$ & $\begin{array}{c}\text { Expected } \\
\text { Deaths }\end{array}$ \\
\hline $25-44$ & 1,198 & $\cdot 03818$ & $\begin{array}{c}45 \cdot 74 \\
45-64\end{array}$ \\
$65-74$ & 990 & $\begin{array}{c}4 \cdot 34710 \\
8 \cdot 58295\end{array}$ & $\begin{array}{r}967 \cdot 01 \\
1,273 \cdot 70 \\
1,278 \cdot 86\end{array}$ \\
$75+$ & 149 & Total Expected & $3,565 \cdot 31$ \\
\hline Total & 2,630 & & \\
\hline
\end{tabular}

Observed Deaths (Ages 25+) $=2,384$

S.M.R. $(100 \times$ Observed $\div$ Expected $)=67$ Standard Error $=100 \sqrt{ }(2384) \div 3,565 \cdot 31$ $=4,882 \cdot 62 \div 3,565 \cdot 31=1 \cdot 4$

\section{(b) Calculation of Inverse S.M.R}

\begin{tabular}{|c|c|c|c|c|}
\hline $\begin{array}{l}\text { Age } \\
\text { (yrs) }\end{array}$ & $x$ & $1 / R$ & $x / R$ & $x / R^{2}$ \\
\hline $\begin{array}{l}25-44 \\
45-64 \\
65-74 \\
75+\end{array}$ & $\begin{array}{r}40 \\
601 \\
817 \\
926\end{array}$ & $\begin{array}{r}26 \cdot 1917 \\
1 \cdot 0238 \\
\cdot 2300 \\
\cdot 1165\end{array}$ & $\begin{array}{r}1,047 \cdot 67 \\
615 \cdot 30 \\
187 \cdot 91 \\
107 \cdot 88\end{array}$ & $\begin{array}{r}27,440 \cdot 21 \\
629 \cdot 95 \\
43 \cdot 22 \\
12 \cdot 57\end{array}$ \\
\hline Total & 2,384 & $\begin{array}{l}\text { Estimated } \\
\text { population }\end{array}$ & $1,958 \cdot 76$ & $28,125 \cdot 95$ \\
\hline
\end{tabular}

(The same notation is used as before: $x=$ No. of deaths, $R=$ age-specific death rate per 1,000 in standardizing population.)

Actual Population $=2,630$ thousand.

Inverse S.M.R $=100 \times 1,958 \cdot 76 \div 2,630=74$

Standard Error $=100 \times \sqrt{ }(28,125 \cdot 95) \div 2,630$

$$
=16,770 \cdot 51 \div 2,630=6 \cdot 4
$$

This illustrates the fact that the standard error of the Inverse S.M.R. is usually greater.

\section{SuMmary}

A new method of standardization is suggested which may be used when the age structure of the population in which the observed deaths occur is not known. The information required consists of the total population, the age structure of the deaths themselves, and the age-specific death rates in some suitable standardizing population. This is ${ }^{*}$ exactly the information most readily available in some practical problems.

The method is not recommended when the standard methods are possible.

\section{REFERENCES}

Registrar General (1954a). "Decennial Supplement (England and Wales) 1951. Occupational Mortality", Part I, p. 4. H.M.S.O., London.

— (1954b). Ibid., p. 6.

(1955). "Statistical Review of England and Wales for 1954", Part I. Tables. Medical. Observed Deaths, p. 235. H.M.S.O., London. 